\title{
Memória e linguagem: uma abordagem sociocognitiva
}

Nathália Luiz de Freitas nathaliadefreitas@yahoo.com.br (UNICAMP), Campinas, São Paulo, Brasil.

\begin{abstract}
RESUMO
O presente trabalho tem como objetivo discutir as relações entre linguagem e memória a partir de uma ótica sociocognitiva que concebe tais instâncias como sendo de caráter biopsicossocial. Para tanto, foram apresentadas e discutidas algumas concepções referentes à Neurociência Cognitiva e à Teoria da Integração Conceptual, além da apresentação de uma análise de dados. Buscou-se mostrar a interdependência entre essas esferas mentais, indicando que, na linguagem, os efeitos de sentido produzidos estão diretamente relacionados a mobilizações mnêmicas, em todos os seus tipos. De igual modo, a construção de memórias, especificamente as declarativas, está ligada à cognição linguística, que as estrutura bem como auxilia em sua consolidação e evocação.
\end{abstract}

PALAVRAS-CHAVE: Linguagem. Memória. Cognição. 


\section{INTRODUÇÃO}

"Penso, logo existo." A afirmação feita pelo filósofo francês René Descartes, no século XVII, a qual consiste em uma das citações mais famosas entre as registradas pela filosofia ocidental, foi a que prevaleceu, durante cerca de trezentos anos, no centro das discussões acerca da problemática envolvendo as entidades corpo e mente. Entretanto, segundo assente Damasio (1996), no livro $O$ Erro de Descartes, o ilustre pensador equivocou-se ao postular que as atividades mentais independem do corpo, de forma que a referida citação deveria ser reformulada para "Existo, logo penso.", haja vista que resultados de pesquisas neurobiológicas modernas indicam que todas as atividades da mente advêm de uma parte especializada do corpo humano, o cérebro. Isso, entretanto, não sugere um reducionismo materialista, indicando, na verdade, a interdependência entre cognição e cérebro.

Além disso, e especificamente para do que trata este trabalho, o pensamento cartesiano deixa de considerar o fato de o ser humano ser conforme é não apenas em virtude de ser capaz de pensar, mas porque pode lembrar-se daquilo que pensa (SQUIRE; KANDEL, 2003), processo que envolve aspectos afetivos, além dos ditos "racionais". Dessa constatação, resulta que cada pensamento, cada palavra proferida, cada ação, as representações que originam o sentido que o indivíduo constrói sobre si mesmo, bem como sua conexão com seus semelhantes, e quaisquer outras atividades inerentes ao homem, são tributárias da memória, ou seja, em termos neurocognitivos, da capacidade que o encéfalo possui para registrar, armazenar e resgatar experiências. Conforme assentem dois dos mais importantes estudiosos da memória, em suas esferas biológica e mental, "a memória é o cimento que une nossa vida mental, o arcabouço que mantém nossa história pessoal e torna possível crescermos e mudarmos ao longo da vida" (SQUIRE; KANDEL, 2003, p.7). No entanto, se o homem se caracteriza por ser capaz de recordar-se daquilo que pensa, ele deve isso à capacidade de linguagem, como se verá adiante.

No que respeita aos estudos que versam sobre associações entre os domínios de memória e de linguagem, conforme aponta Cruz (2004), é recorrente que se tome a memória, em sua esfera cognitiva, como um tipo de processamento mental da informação a serviço da linguagem, sendo esta uma função privilegiada da cognição. Trata-se de uma discussão já relativamente antiga, que remonta à perspectiva modularista de mente e, por conseguinte, de linguagem, teorizadas por Fodor e Chomsky, respectivamente. Conforme Chomsky, haveria o isolamento funcional dos processos algorítmicos de linguagem com relação aos outros processos mentais $(1957 ; 1971)$. Contudo, a adoção dessa perspectiva, além de separar domínios interdependentes e complementares, relega a memória a um lugar meramente estruturador, o qual não condiz com a complexidade do sistema cognitivo humano, do qual ela é participante fundamental. Recusa-se, na presente abordagem, que memória e linguagem tenham funções meramente representacionais e referenciais, admitindo-se que tais domínios possuem caráter recíproco, de maneira a serem as interações humanas e suas contingências pragmáticas os fatores que colocam esses processos sociocognitivos em relação.

Ao serem discutidas as relações entre linguagem e memória, é praticamente instantâneo o surgimento de uma reflexão tangente à cognição. De acordo com o 
que assente Marcuschi (2003), é necessário que se delimite com clareza do que se trata tal conceito para que ele não seja vago e, consequentemente, possa se referir a uma série de fatos. Nas palavras do estudioso: "acredito que assim como nos anos 60 e 70 do século XX se abusou da palavra 'estrutura' a ponto de esvaziá-la de algum sentido, hoje corre-se o risco de abusar da expressão cognição a ponto de tirar-Ihe qualquer sentido mais preciso" (2003, p. 60). Concebemos ser a cognição, mais adequadamente denominada de cognição social, a capacidade intersubjetiva e perspectivada - de cada organismo compreender os coespecíficos como seres iguais a ele, com vidas mentais e intencionais iguais às dele (TOMASELLO, 2003).

As interfaces existentes entre linguagem e memória são aqui concebidas através de uma ótica sociocognitiva que compreende a cognição humana por meio de processos interativos e (inter) subjetivos humanos, do trabalho linguísticodiscursivo dos indivíduos e de suas experiências socioculturais, assim como das condições pragmáticas, históricas e ideológicas que orientam a ação desse sujeito no mundo. Nesse modo de entender, todos os referidos processos mobilizam e constituem a relação entre mundo social e mundo mental.

Diante do exposto, o presente trabalho tem como objetivo discutir as relações entre linguagem e memória a partir de uma ótica sociocognitiva (SALOMÃO, 1999; TOMASELLO, 2003), que concebe tais instâncias como sendo de caráter biopsicossocial. Para tanto, serão feitas reflexões com base em expoentes teóricos significativos, no cenário acadêmico, sobre os domínios em questão, além da apresentação de uma análise de dados. A finalidade deste artigo é trazer para o bojo das discussões em Linguística a relevância de se conceber linguagem e memória de modo inter-relacionado, tendo em vista a repercussão que o funcionamento dessas esferas sociocognitivas tem para a vida humana.

\section{MEMÓRIA}

No que se refere ao construto memória, importa destacar que variadas são as abordagens conferidas a ele. Jacques Le Goff (1996), em livro intitulado História e Memória, busca realizar um apanhado, que não se pretende exaustivo nem pontual, sobre as investigações da memória em diferentes épocas. De acordo com o historiador, têm-se: i) a memória coletiva dos povos sem escrita, isto é, a memória étnica; ii) a memória coletiva perpassada pela escrita, especificamente sob as formas de comemoração e de documento, a qual surge durante a transição da Pré-história para a Antiguidade; iii) a memória coletiva medieval ocidental, que, tendo como característica principal sua cristianização, divide-se em memória litúrgica, então dominante, e memória laica, de incipiente penetração cronológica; iv) a memória coletiva escrita e figurada, presente desde a Renascença até a atualidade, forma marcada pela invenção da imprensa, domínio que possibilitou tanto a ampliação e a difusão da memória coletiva, quanto a exteriorização progressiva da memória individual; e v) a memória contemporânea, tipificação que abrange esferas científicas como a memória artificial - eletrônica, a memória psíquica, a memória cognitiva, a memória genética e a memória coletiva socioculturalmente modificada ao longo das transformações históricas. 
Nesse contexto, cumpre esclarecer que o domínio memória é plural, de maneira que a perspectiva teórica adotada no texto ora apresentado consiste em um recorte do referido objeto frente a várias outras possíveis focalizações. Aliado a isso, está o fato de se considerar aqui o termo memória, no singular, para denominar a capacidade geral do cérebro e de demais sistemas - culturais, sociais, computacionais etc. - de atuação nos processos de aquisição, armazenagem e recordação de informações; e a expressão memórias para denotar cada uma ou cada tipo delas (IZQUIERDO, 2011). Ao se levar em conta que as memórias humanas provêm das experiências dos indivíduos, tal conceituação torna-se bastante plausível, considerando-se que há (ou poderia haver) tantas memórias quanto experiências possíveis.

Em seu sentido amplo, conforme aponta Izquierdo (2011), a expressão memória se refere tanto aos mecanismos operantes na placa de um computador, quanto à história de uma nação, povo ou civilização, o que incluem as memórias individuais dos sujeitos que a compõem. Contudo, em cada situação, tal vocábulo diz respeito a algo bem específico, haja vista que os mecanismos de aquisição, armazenamento e evocação são diferentes a depender do tipo de memória enfocada. Nessa perspectiva, pode-se afirmar que é o conjunto das memórias que constitui a identidade, seja ela de um povo ou de um indivíduo. No primeiro caso, é possível assentir que tal identidade coletiva é, grosso modo, formada pelas memórias comuns dos indivíduos que compõem o povo em questão, as quais, por sua vez, são o fator responsável pela união de indivíduos em grupos, que originarão povos, nações e civilizações. Nesse prisma, a memória é fator primordial tanto na formação de determinado grupo social, quanto na construção de sua identidade. No que se refere à identidade individual, de acordo com o que postula Izquierdo (2011), é justamente o acervo de memórias do sujeito que o torna indivíduo. Quando a voz do senso comum ressoa dizendo que cada pessoa é única, uma explicação científica possível para isso reside no fato de cada indivíduo possuir um conjunto de memórias exclusivo, diferente dos acervos dos demais, portanto autêntico. Essa coleção individual de lembranças tem como alicerce de formação diversas fontes, entre as quais a experiência é uma das mais importantes. Disso advém que nem mesmo gêmeos univitelinos ou seres clonados possuem, entre seus pares, as mesmas memórias.

Em termos cognitivos, memória é a denominação conferida aos mecanismos de aquisição, formação, conservação e evocação de informações (IZQUIERDO, 2011). No que se refere aos mecanismos essenciais, às áreas nervosas envolvidas e ao mecanismo molecular de operação, a memória humana é semelhante à dos demais mamíferos, diferindo, entretanto, quanto ao conteúdo, já que, por exemplo, um homem com memória ausente de patologia mnésica é capaz de se lembrar de melodias e letras de canções, já um rato ou um cachorro não. Isso se deve ao fato de que os seres humanos começam a utilizar a linguagem para adquirir, codificar, guardar ou evocar as memórias, por volta dos 2 a 3 anos, ao passo que os demais animais não são capazes de fazê-lo. Dessa forma, tanto os seres humanos quanto as demais espécies animais ativam aproximadamente as mesmas regiões cerebrais, exceto as áreas relacionadas à linguagem, para os processos de formação e de evocação de memórias. Observa-se, portanto, que a faculdade de linguagem é determinante na constituição de memórias complexas, exclusivas aos seres humanos. 
As memórias são produzidas pelos neurônios, células nervosas responsáveis por muitas outras atividades cognitivas, armazenam-se em redes neuronais e são evocadas pelas redes de neurônios em que foram guardadas ou por redes diferentes dessas. Além disso, são moduladas pelos estados de ânimo, pelas emoções e pelo nível de consciência, sendo os dois primeiros os maiores reguladores da aquisição, da formação e da evocação das memórias. Isso quer dizer que as pessoas costumam lembrar-se melhor, ou seja, com mais detalhes, de episódios emocionalmente mais significativos, que, por seu turno, são passíveis de alterar os estados de ânimo. Faz-se importante enfatizar que a lembrança não corresponde fielmente à realidade, já que, durante a aquisição mnêmica, o cérebro converte a realidade em códigos, de maneira a evocá-la também sob a forma codificada. Há, dessa maneira, a ativação de dois processos tradutórios, sendo que um ocorre entre a realidade das experiências e sua correspondente formação de memória, e o outro entre tal memória formada e sua evocação. A existência dos referidos processos tradutórios advém do fato de que, em todas as etapas mnêmicas, as complexas redes neuronais ativadas utilizam códigos e processos que não são iguais à realidade da qual extraem ou para a qual revertem as informações (IZQUIERDO, 2011).

Do mesmo modo que a tradução de textos entre línguas diferentes provoca mudanças, sejam estruturais ou semânticas, o que, por conseguinte, pode levar a perdas de efeitos de sentido, ao se comparar a obra original com a traduzida (TRAVAGLIA, 2003), a conversão da realidade em um código complexo de sinais elétricos e bioquímicos e a posterior reversão dessa informação com vistas à evocação, mecanismos estes realizados pelos neurônios, levam, necessariamente, a uma reconfiguração dos fatos experienciados. No momento da evocação mnêmica, é preciso que o cérebro, em instantes, recrie memórias que exigiram horas para serem consolidadas. Em ambos os casos, traduzir não significa apenas informar em um código diferente do da fonte, mas, antes, transformar (IZQUIERDO, 2002).

Considerando que incontáveis são as experiências dos seres humanos, há um fator crucial relativo à construção das memórias, qual seja, o esquecimento. De acordo com McGaugh (2000), a característica mais notável da memória consiste no esquecimento. Isso porque, se o homem, ou qualquer outra espécie animal, fosse capaz de se recordar de todos os episódios vivenciados, o convívio com os demais membros do seu grupo seria impossível. Trata-se de um esquecimento adaptativo, principalmente no que se refere aos acontecimentos desagradáveis. "Os leigos geralmente consideram o esquecimento como um dos mais frustrantes aspectos de suas mentes. Entretanto, numerosos teóricos da memória já mostraram que o esquecimento pode ser bastante adaptativo" (ANDERSON, 2005, p. 174). A maioria de toda a aquisição mnêmica que o indivíduo constrói em sua vida é perdida. Além disso, muitas experiências nem chegam a fazer parte da memória de longo prazo, um dos tipos de memória que serão discutidos a seguir.

No campo cognitivo, a memória é classificada quanto à função - memória de trabalho e de armazenamento -, ao conteúdo - procedimentais e declarativas - e ao tempo de duração - de curta e de longa duração. No que se refere à função, a memória de trabalho, também denominada memória online, funciona no instante em que a informação está sendo levada à mente; dura, no máximo, três minutos e não produz arquivos, diferentemente das demais formas de memória, que pertencem ao tipo de armazenamento. A memória de trabalho tem a função de 
recordar algo dito há poucos segundos, como, por exemplo, o número de um telefone. Nesse caso, a pessoa, cujos processos mnêmicos estão sendo ativados, retém esses dígitos até o momento de discá-los, de modo a descartá-los após sua utilização. A memória de trabalho consiste no meio de entrada da informação, operando como o gerenciador geral, tendo em vista que tal mecanismo, ao entrar em contato com novos dados, consulta as memórias de curto e de longo prazo com o propósito de verificar se esses estímulos são realmente novos e relevantes (IZQUIERDO, 2011; STERNBERG, 2000).

No que concerne ao conteúdo, as memórias são agrupadas em procedimentais e declarativas. A memória procedimental, ou procedural, diz respeito ao saber fazer. Consiste em "capacidades ou habilidades motoras ou sensoriais que habitualmente chamamos de hábitos" (IZQUIERDO, 2002, p. 23). Um exemplo típico é a atividade de andar de bicicleta. Esse tipo de memória é menos suscetível ao esquecimento e, embora também seja modulada pelas emoções, sofre menos influência delas. A memória declarativa, responsável pelo registro de fatos, eventos e conhecimentos, é subdividida em semântica e episódica. A primeira tange aos conhecimentos gerais que o ser humano retém, tais como informações sobre as regras gramaticais de determinada língua, fórmulas matemáticas e espécies de animais. Já a memória declarativa episódica, igualmente denominada de autobiográfica, abrange as recordações de eventos em que o sujeito que formou a memória participou ou assistiu, como, por exemplo, uma apresentação artística, um acidente de trânsito, uma conversa com certo colega.

Ainda com relação à distinção entre memórias procedural e declarativa, outro apontamento é cabível. Enquanto aquela é, geralmente, implícita (evocada de forma inconsciente), esta é explícita. Para ilustrar tal diferenciação, segue o posicionamento de Squire e Kandel (2003, p. 187): “O sentimento é uma memória, com certeza, porque é baseado na experiência, mas essa memória é inconsciente, não-declarativa, além de independente da capacidade de lembrança consciente." Esse é um exemplo de memória implícita. A memória explícita, por sua vez, pode ser explicada. Vale ressaltar, contudo, que existem algumas memórias declarativas semânticas que são implícitas, como o aprendizado da língua materna. De igual modo, é possível haver mobilidades de memórias quanto ao seu tipo, isto é, uma memória declarativa pode passar a procedimental, sendo um exemplo o ato de dirigir um automóvel.

Quanto ao tempo de duração, as memórias podem ser de curta ou de longa duração (prazo). A memória denominada de curta duração é aquela que compreende desde os primeiros segundos ou minutos após o aprendizado até de três a seis horas depois, isto é, o tempo gasto para a memória de longa duração ser formada (IZQUIERDO, 2002). Sua função é, basicamente, manter o sujeito em condições adequadas para responder cognitivamente por meio de uma cópia passageira da memória principal, a qual ainda está em processo de formação. Para se ter uma ideia de seu funcionamento, quando um indivíduo está lendo a terceira página de um livro, a memória de curto prazo oferece suporte cognitivo para que esse leitor se recorde das duas páginas anteriores. Ao atuar como um tipo de alojamento temporário da informação, à medida que a memória de longa duração tem sua consolidação, a memória de curta duração vai sendo substituída por tal processo mnêmico definitivo. Memória de longa duração é a expressão empregada para denominar aquelas memórias que persistem, no mínimo, seis horas e que, a 
depender da modulação que nela atuou, da consistência referente ao seu processo de armazenamento e da frequência com que é reconstruída, pode perdurar por toda uma vida, recebendo, diante de tamanha persistência, a classificação de memória remota (IZQUIERDO et. al., 2006).

Importa ressaltar que os mecanismos mnêmicos descritos em termos cognitivos, com algumas menções de caráter biológico, estão intimamente relacionados a elementos socioculturais. Isso porque, em primeiro lugar, qualquer formação de memória depende de um processo de experienciação, que envolve interações entre o sujeito que experiencia e o meio em que está. Em segundo lugar, em razão de o homem ser de natureza social, de modo a fazer parte de uma cultura e estar imbuído dela, o que configura o seu sistema cognitivo, conferindo a ele o caráter sociocognitivo por excelência.

\section{LINGUAGEM}

Uma abordagem sociocognitiva de linguagem entende tal instância como atividade coletiva que reflete a cognição e a cultura, de forma indissociável (FERRARI, 2011). Essa acepção rompe com a dicotomia cartesiana corpo e mente, uma vez que as duas entidades são interdependentes no processo de produção de linguagem e, consequentemente, de sentido. A compreensão de mundo só é possível no interior daquilo que o sujeito vivencia, dentro das experiências do indivíduo que estão associadas à dimensão sociocultural da qual participa, dimensão esta fornecedora de conceitos que estão em constante remolduração.

Segundo Martelotta e Palomanes (2008), esse sociocognitivismo admite a existência de determinados processos de utilização de estruturas linguísticas, bem como sua adequação aos contextos reais em que elas são constituídas, para abordar os mecanismos de significação. De acordo com os autores, tal proposta considera aspectos relativos a restrições cognitivas, entre as quais estão a captação de dados, sua compreensão e armazenamento na memória, bem como a capacidade de organização, conexão, acesso, utilização e transmissão eficiente de dados. Trata-se de uma perspectiva que concebe a linguagem como parte integrante da cognição, em oposição à concepção modular chomskyana, de modo que tal domínio fundamenta-se em processos cognitivos, sociointeracionais e culturais, devendo ser estudado a partir do seu uso e do contexto da conceptualização, do processamento mental, da interação, bem como da experiência social e cultural.

A abordagem de tais fatores não inviabiliza reflexões acerca do funcionamento da mente, pelo contrário, além de propiciar tal perspectiva, possibilita a inserção do sujeito no espaço social e cultural, de maneira a fornecer um panorama mais próximo do real, no que se refere à dinâmica comunicacional. Dessa forma, a referida proposta cognitivista emprega o termo "sócio" para agregar-se à interação social, expressão que salienta o caráter social da cognição e a importância do contexto nos processos de significação. Tem-se, portanto, a perspectiva sociocognitiva da linguagem, cuja premissa fundamental consiste na indeterminação do significado, isto é, a linguagem não carrega o sentido, ele é construído socialmente e necessita do partilhamento, consentimento e cooperação entre interlocutores (SALOMÃO, 1999). 
O significado consiste no fenômeno linguístico primário, na impossibilidade de dissociação entre significado linguístico e conhecimento de mundo, e, finalmente, na máxima de que a linguagem não espelha o conhecimento, mas o interpreta, o constrói e o organiza de forma a refletir os interesses, as necessidades e as experiências dos sujeitos e das culturas de que estão imbuídos (CHIAVEGATTO, 2009). Assentado nesses princípios está o posicionamento filosóficoepistemológico denominado Experiencialismo ou Realismo Corporificado (LAKOFF; JOHNSON, 1980; LAKOFF, 1987), metodologicamente pautado na análise do uso linguístico real. Johnson (1987) sugere que o corpo delimita a experiência e estrutura a cognição, sendo que conceitos rudimentares resultam da experiência humana pré-conceptual. A concepção de que a linguagem não reflete diretamente o mundo - na verdade, ela o constrói - é sustentada pelo paradigma experiencialista. Segundo Jackendoff (1983), trata-se de representações mentais sobre a realidade, baseadas nas construções da mente humana a partir dos sistemas perceptuais e conceptuais, ou seja, uma realidade projetada. Lakoff (1987) concebe que, tendo em vista a forma e a configuração dos cérebros e corpos humanos, os indivíduos estabelecem uma perspectiva particular entre várias possíveis e também viáveis perante o mundo.

Quanto às teorias linguísticas pautadas em uma abordagem sociocognitiva de linguagem, a Teoria da Integração Conceptual (FAUCONNIER; TUNER, 2002) consiste em expoente significativo. Baseada na Teoria dos Espaços Mentais (FAUCONNIER, 1994), a Teoria da Integração Conceptual tem como objetivo explicar o que acontece na mente humana durante o processamento cognitivo, no qual estão inseridos os processos de significação. De acordo com tal perspectiva, o funcionamento do cérebro é ininterrupto, ocorrendo através de ativações cerebrais bastante intensas, as quais levam a construções mentais complexas que surgem à medida que o ser humano pensa, fala, age etc.. Tal mecanismo seria uma capacidade humana peculiar, que possibilita a construção de conjuntos de memórias passíveis de serem ativadas sempre que necessário.

A Teoria da Integração Conceptual assente que o ser humano foi capaz de desenvolver, frente aos demais animais, demasiada capacidade de inovar, através da imaginação, da proposição de identidade entre conceitos e de sua integração e, então, criar redes - modelos - de pensamento e de ação. A criação dessas redes refere-se a um conjunto de projeções de relações vitais, como, por exemplo, tempo, espaço, causa e efeito, analogia, identidade e mudança. Para desenvolver tais redes, o indivíduo conecta espaços mentais - ativações cerebrais que demandam a interrelação neuronial processada em espaço/tempo efêmeros, responsáveis pela estruturação de informações relevantes em um determinado momento - e os relaciona a conhecimentos relativamente estáveis (conhecimentos prévios), armazenados na memória de longo prazo.

Os espaços mentais são, então, caracterizados como uma forma de abstração complexa - alicerçada em generalizações - que permitem a formulação de hipóteses acerca do pensamento, da linguagem e de outros aspectos da vida humana. Tais espaços seriam constituídos para atender a uma demanda específica, ao mesmo tempo em que seriam criados e desfeitos conforme determinadas exigências contextuais. De acordo com Fauconnier (apud COSCARELLI): 
Os espaços mentais são pequenos conjuntos de memória de trabalho que construímos enquanto pensamos e falamos. Nós os conectamos entre si e também os relacionamos a conhecimentos mais estáveis. Para isso, conhecimentos linguísticos e gramaticais fornecem muitas evidências para essas atividades mentais implícitas e para as conexões dos espaços mentais (2005, p. 291).

Segundo essa perspectiva, a memória de trabalho é fundamental para a construção de sentidos, já que sua ativação constitui os elementos estruturantes do pensamento e da linguagem, os espaços mentais. Ademais, são as memórias de longo prazo que, em sua interconexão com a memória de trabalho no momento da ativação dos espaços mentais, permitem a configuração dos efeitos de sentido durante o processo de significação.

Conforme a proposta da Integração Conceptual, o que caracteriza a espécie humana é a capacidade de associar diversos espaços mentais e, especialmente, a capacidade de constituir novos espaços - espaço mesclado - enquanto o sujeito realiza atividades cotidianas. Assim, o espaço mesclado consiste no resultado da combinação de, no mínimo, dois espaços mentais, a partir dos quais a mente imagina identidades e cria um terceiro espaço, através da integração dessas atividades. Fauconnier (1997) afirma que a mescla "é um poderoso processo de construção de sentido online; é dinâmica, flexível e ativa no pensamento".

Para que a mesclagem ocorra, é necessário que, pelo menos, quatro domínios sejam ativados: dois espaços mentais de origem, um espaço genérico e o domínio mescla, que abarcará traços dos demais domínios (FAUCONNIER, 1997). São exigidos esses componentes em razão de, segundo assente Salomão (1998), o princípio central da cognição humana corresponder à projeção entre domínios, do que advém o fracionamento, bem como a transferência de informação e o processamento do sentido. Os domínios são constituídos com base em agrupamentos de conhecimentos oriundos de experiências, os quais são estruturados e organizados, podendo ser classificados em domínios estáveis e em domínios locais (os espaços mentais).

Os domínios estáveis consistem no legado da humanidade, já que se referem às estruturas de memória pessoal ou social - esquemas e frames - evocados em operações de significação. São de três ordens: i) Modelos Cognitivos Idealizados ( $\mathrm{MCls}$ ): ideários construídos em sociedade e veiculados culturalmente, caracterizados por sua estabilidade como dimensões cognitivas identificáveis e evocáveis, bem como pela organização interna das informações que os compõem e pela flexibilidade de sua instanciação, de acordo com as necessidades locais manifestadas (SALOMÃO, 1999); ii) Molduras Comunicativas - os frames (molduras em que as experiências são encaixadas) mobilizados no evento, por meio dos quais é possível identificar a natureza das atividades comunicativas em curso; iii) Esquemas Genéricos - esquemas conceptuais de caráter abstrato, referentes a expectativas desencarnadas. As projeções entre domínios, por seu turno, são responsáveis pela transferência de informações entre entidades do mesmo ou de outro domínio, o que expande a significação do primeiro para o segundo item, de forma a gerar novos significados.

As projeções de conceitos realizadas entre domínios têm caráter fundamental para o desenvolvimento da mesclagem (blending), um processo cognitivo que 
opera sobre dois espaços mentais com a finalidade de projetar sentidos em um terceiro espaço, o espaço mescla (FAUCONNIER; SWEETSER, 1996). Os significados projetados no espaço mescla (espaço transitório em que as informações advindas dos espaços mentais de origem são organizadas) são associados em novo contexto, havendo a permanência de aspectos dos significados originais e a incorporação de significações criadas. A mesclagem é o resultado do rearranjo entre as projeções feitas e a situação comunicativa em que elas acontecem.

Nessa ótica, o domínio-mescla é um terceiro espaço específico constituído com base na associação entre dois espaços mentais, dos quais incorpora estruturas parciais, para que forme uma estrutura emergente autêntica que representará uma dimensão inédita. Quando, por exemplo, se diz "mão de vaca", em referência a uma pessoa, o substantivo composto construído é uma mesclagem, já que herda aspectos significativos dos termos básicos (mão e vaca), ao passo que novos significados, oriundos das correlações que essas construções ativam no contexto em que ocorrem, são criados. Dessa forma, os significados são processados na mente do sujeito interpretante por meio da recuperação das projeções importadas para a mescla. A mesclagem é o processo sociocognitivo responsável pela criatividade na linguagem, assim como pelas novas configurações e relações que confere aos sentidos por ela combinados, dos quais surgem novas significações e conceptualizações (MIRANDA, 1999).

$\mathrm{Na}$ tentativa de explicar a cognição humana, a teoria em questão enfoca as atividades de caráter linguístico, uma vez que concebe a linguagem como sendo o principal meio de acesso ao conhecimento e também sua mais eficiente forma de expressão. Seus autores advogam pela interligação das operações cognitivas, linguagem, pensamento e ação. A Teoria da Integração Conceptual admite que a cognição humana é fortemente dependente do contexto e, por isso, propõe-se a analisar os tipos de conexão realizados pela mente e os efeitos de sentido daí gerados, surgidos, conforme a linguagem utilizada, em contextos específicos (CHIAVEGATTO, 1999).

\section{MEMÓRIA E LINGUAGEM: ASPECTOS EPISTEMOLÓGICOS}

Ainda no que se refere à concepção de cognição, faz-se importante a explicitação das bases epistemológicas que subjazem a presente perspectiva. Levando-se em conta o postulado de duas formas de manipulação mental das informações recebidas pelo organismo, em série - operações realizadas uma após a outra - e em paralelo - desenvolvimento simultâneo de múltiplas operações (STENBERG, 2000), é aqui assumido que o processamento da informação complexa pelos seres humanos, tais como os processos linguísticos e mnêmicos declarativos, se dá pela distribuição em paralelo, pois tal hipótese confere uma explicação plausível sobre a rapidez do referido fenômeno. 0 modo serial seria responsável pela efetivação de tarefas que envolvem apenas uma categoria de informações, enquanto o paralelo trataria de informações referentes a mais de uma categoria, responsabilizando-se, portanto, pelo processamento complexo de informações.

O Processamento Distribuído em Paralelo (PDP), ou Abordagens Conexionistas, tem como aspecto fundamental a noção de redes de memória que, segundo Sternberg (2000), são um conjunto de elementos ou conceitos 
interconectados. Esses elementos (ou conceitos) são denominados de "nós da rede", ou nódulos. Cada nódulo se conecta a muitos outros nós, de forma que esse emaranhado de conceitos interconectados permite ao indivíduo a organização do conhecimento nas conexões entre os diversos nódulos, isto é, reflete a capacidade do ser humano em manter e tratar diferentes informações de modo simultâneo, e eficazmente, por meio de uma rede distribuída através de inúmeros locais no cérebro. Todo esse Processamento seria regido pelo Sistema Nervoso, cuja função consistiria na transmissão e na manipulação das informações oriundas do ambiente, o meio social. Essas informações seriam captadas pelos órgãos dos sentidos, de forma a constituírem o input a ser processado pelo Sistema Nervoso, - qual tenderia, após complexos mecanismos que envolvem capacidades sociocognitivas, a gerar um output, uma resposta (DORON; PAROT, 2001).

Diante do exposto, depreende-se que processos cognitivos complexos, como a linguagem e a memória, são distribuídos em paralelo, isto é, os mecanismos concernentes a cada um deles operam em conjunto, em concomitância, embora seus constituintes simples possam ter configuração modular. Além disso, sendo processos cognitivos interdependentes, a memória e a linguagem atuam conjuntamente, seja para a aquisição, consolidação e acesso a um arquivo mnêmico declarativo, seja para a produção ou interpretação de uma elocução. Trata-se de evidências de caráter neurobiológico e neurofisiológico que ajudam a sustentar a ideia de interdependência entre memória e linguagem. Nessa ótica, as funções cognitivas abrangem um sistema de atividades mentais que se integram e se inter-relacionam, tais como linguagem, raciocínio, percepção, atenção e memória (STELLA, 2004).

\title{
INDISSOCIABILIDADE ENTRE MEMÓRIA E LINGUAGEM: UMA EXEMPLIFICAÇÃO
}

A mútua constituição da linguagem com a memória pode ser verificada em todas as atividades linguístico-cognitivas do homem. Para ilustrar essa indissociabilidade, é apresentada uma análise do ponto de vista do processamento linguístico-mnêmico requerido à interpretação da seguinte piada, através da proposta da Integração Conceptual:

\author{
"A tia vira-se para a Mariazinha e pergunta: \\ -O que você vai fazer quando for grandona como a titia? \\ -Um regime!"
}

A piada em análise aciona o nível linguístico lexical. Para se compreendê-la, é preciso que seja notada a comparação realizada entre a sentença: "O que você vai fazer quando for grandona como a titia?", e a frase já cristalizada culturalmente: "O que você vai fazer quando crescer?". A "chave" humorística está alicerçada na ambiguidade que o vocábulo "grandona" possui, o qual pode significar "bastante grande", "alta", "crescida", "adulta" ou "gorda". Além disso, tem-se o 
conhecimento tácito de que crianças, geralmente, falam o que pensam e a verdade, fator que, nesse chiste, quebra a expectativa gerada pelo enunciado da tia.

A polissemia gerada pela expressão "grandona" é responsável pelo surgimento de dois domínios-fonte, espaços mentais distintos em que estão presentes dois $\mathrm{MCl}^{\prime}$, sendo um, canônico e aguardado, concernente à fase adulta e outro, inesperado, relativo à "acima do peso" - e escolhido pelo personagem sobrinha -, ambos referentes ao personagem da tia, os quais criarão um espaço genérico, cuja projeção é de dimensão/tamanho, levando ao domínio mescla grandona-adulta-gorda.

Os dois domínios-fonte, que são espaços mentais - portanto, envolvem significativamente a memória de trabalho, advém de acessos mnêmicos possibilitados pelo conhecimento léxico-semântico e pelo conhecimento pragmático do termo "grandona". No primeiro domínio-fonte, canônico, os atributos semânticos do termo estão no léxico mental do falante da língua, isto é, em sua memória de longa duração, que é acessada imediatamente após a enunciação da primeira frase. O segundo domínio-fonte, inesperado, surge por meio do processamento associativo de elementos da memória de longa duração com aspectos relacionados ao seu contexto enunciativo, entre os quais está o fato de se tratar de uma piada, gênero textual-discursivo que autoriza a manipulação dos sentidos potenciais do termo "grandona", a qual só é realizada ao final da enunciação. Esse processamento associativo envolve de forma fundamental o funcionamento da memória de trabalho.

A memória de trabalho é extremamente necessária para a criação do espaço genérico e do domínio-mescla, considerando sua atuação na seletividade dos sentidos proeminentes na cena enunciativa com vistas à atribuição relevante de significado plausível. À medida que essa piada é conhecida e aprendida, passa a fazer parte do repertório mnêmico do indivíduo, compondo sua memória de longa duração.

\section{CONCLUSÃO}

O vínculo cognitivo entre memória e linguagem é evidente quando se trata de memórias declarativas, constatação esta que pode ser observada tanto em termos filogenéticos, quanto ontogenéticos. Com relação ao primeiro fator, tem-se que esse tipo de memória é exclusivo da espécie humana, a única, entre os demais seres vivos, que possui linguagem articulada, aspecto crucial para que sejam formadas. No que se refere ao segundo, há o fato de que somente quando a criança está em processo de aquisição da linguagem, por volta dos dois anos de idade, as memórias declarativas começam a ser formadas, o que indica a imprescindibilidade da linguagem para o advento de tal tipo de memória.

Conforme se tentou mostrar, as memórias de trabalho e de longo prazo desempenham papeis preponderantes no processo de significação, uma vez que, de acordo com a perspectiva da Integração Conceptual, a memória online é, no seu conjunto, o componente dos espaços mentais, estrutura básica da construção de sentidos, e a de longo prazo consiste no rol de estruturas que alimentam os espaços mentais, levando, consequentemente, à construção dinâmica de 
conceitos, a qual ocorre através de projeções e culmina, em grande parte das situações, em uma mesclagem. Desde os processos mais simples de significação, como o acesso ao léxico mental, até o mais complexo, grupo em que se encontram a formulação de suposições e de inferências, tem-se a atuação efetiva dos dois tipos de memória referidos.

A interdependência entre memória e linguagem é robustamente evidenciada em casos de prejuízos em uma dessas instâncias, como o que ocorre nos quadros de afasia e da doença de Alzheimer. Enquanto naquela, o déficit de linguagem ocasiona perturbações nos processos mnêmicos, tendo em vista a frequente condição de anomia, esta tem como um dos sintomas secundários, e necessário para o próprio diagnóstico da neurodegenerescência, a alteração de linguagem, que ocorre, em seus diferentes níveis, nos três estágios da doença (FREITAS, 2012). O perfil sociocognitivo da doença de Alzheimer fornece um panorama evidente das relações entre memória e linguagem, uma vez que, nesse processo demencial, as duas esferas vão, com o avanço da doença, se deteriorando, em uma escala que vai, entre o primeiro e o terceiro estágio, da memória de trabalho à memória de longo prazo e do nível pragmático ao nível fonológico de linguagem.

Buscou-se, neste trabalho, discutir sobre a interdependência sociocognitiva entre memória e linguagem, no que se refere tanto aos processos efetivamente linguísticos quanto aos eminentemente mnêmicos. Por meio de conceitos da Teoria da Integração Conceptual aliados a achados da Neurociência Cognitiva, tentou-se mostrar que a temática em questão pode e deve fazer parte dos estudos em Linguística, considerando a linguagem como um objeto sociocognitivo que é perpassado, constituído e influenciado pelas demais esferas mentais. 


\title{
Memory And Language: An Approach Sociocognitive
}

\begin{abstract}
This paper discusses the relationship between language and memory from a socio-cognitive perspective that conceives such instances as the biopsychosocial character. For that were presented and discussed some concepts related to Cognitive Neuroscience and Theory of Conceptual Integration, in addition to the presentation of a data analysis. We tried to show the interdependence of these mental spheres. In language, the effects produced are directly related to meaning mnemic mobilizations in all its types. Similarly, the construction of memories, specifically declarative, is on the linguistic cognition, the structure and assist in its consolidation and evocation.
\end{abstract}

KEYWORDS: Language. Memory. Cognition 


\section{REFERÊNCIAS}

ANDERSON, J. R. Aprendizagem e memória. Trad. de Juliana Saad. 2. ed. São Paulo: LCT, 2005.

CHIAVEGATTO, V. C. Um "olhar" sobre o processo cognitivo de mesclagem de vozes. Veredas: revista de estudos linguísticos. v. 3, no 1, Juiz de Fora, Editora da UFJF, jan/jun 1999, p. 97-114.

CHIAVEGATTO, V. C. Introdução à linguística cognitiva. Rio de Janeiro, Matraga, v. 16, no 4, jan./jun. 2009, p. 77-96.

CHOMSKY, N. Linguagem e pensamento. Petrópolis (RJ): Vozes, 1971.

CHOMSKY, N. Syntactic Structures. The Hague: Mouton, 1957.

COSCARELLI, C. V. Entrevista: Uma conversa com Gilles Fauconnier. Revista Brasileira de Linguística Aplicada, v.5. no 2. 2005. p. 291-303.

CRUZ, F. M. Uma perspectiva enunciativa das relações entre linguagem e memória no campo da Neurolinguística. 2004. 204p. Dissertação (Mestrado em Linguística) - Instituto de Estudos da Linguagem da Universidade Estadual de Campinas, Campinas, 2004.

CRUZ, F. M. Linguagem, interação e cognição na doença de Alzheimer. Tese (Doutorado) DAMÁSIO, A. O Erro de Descartes. São Paulo: Companhia das Letras, 1996.

DORON, R.; PAROT, F. Dicionário de Psicologia. São Paulo: Ática, 2001.

FAUCONNIER, G. Mental Spaces: Aspects of Meaning Construction in Natural Language. Cambridge: Cambridge University Press, 1994.

FAUCONNIER, G. Mappings in Thought and Language. Cambridge: Cambridge University Press, 1997.

FAUCONNIER, G.; SWEETSER, E. Spaces, world and grammar. Chicago/London: The 
FAUCONNIER, G.; TURNER, M. The Way We Think: Conceptual Blending and the Mind's Hidden Complexities. New York: Basic Books, 2002.

FERRARI, L. Introdução à Linguística Cognitiva. São Paulo: Contexto, 2011.

IZQUIERDO, I. Memória. Porto alegre: Artmed, 2002.

IZQUIERDO, I. Memória. Porto alegre: Artmed, 2011.

IZQUIERDO, I; BEVILAQUA, L.R.M.; CAMMAROTA, M. A Arte de Esquecer. Estudos Avançados. São Paulo, v.20, no 58, set/dez. 2006.

JACKENDOFF, R. Semantics and Cognition. Cambridge (MA): MIT Press, 1983.

JOHNSON, M. The body in the mind. Chicago: The University of Chicago Press, 1987.

LAKOFF, G.; JOHNSON, M. Metaphors we live by. Chicago: University of Chicago Press, 1980.

LAKOFF, G. Women, fire and dangerous things. Chicago, University of Chicago Press, 1987.

LE GOFF, J. História e Memória. Campinas, SP: Editora da UNICAMP, 1996.

MARCUSCHI, L. A. Do código para a cognição: o processo referencial como atividade cognitiva. Veredas, v. 10, p. 43-62, 2003.

MARTELOTTA, M. E.; PALOMANES, R. A linguística cognitiva. In: MARTELOTTA, M. E. (Org.). Manual de linguística. São Paulo: Contexto, 2008.

MIRANDA, N. S. Domínios conceptuais e projeções entre domínios: uma introdução ao modelo dos espaços mentais. Veredas: revista.

SALOMÃO, M. M. M. A questão da construção do sentido e a revisão da agenda dos estudos da linguagem. Veredas: revista de estudos linguísticos. Juiz de Fora, v.3, no 1, p. 61-79, 1999. 
SQUIRE, L.; KANDEL, E. Memória: da mente às moléculas. Porto Alegre: Artmed, 2003.

STERNBERG, R. Psicologia Cognitiva. Porto Alegre: Artmed, 2000.

STELLA, F. Funções cognitivas e envelhecimento. In: PY, I. (Org.). Tempo de envelhecer: percursos e dimensões sociais. Rio de Janeiro: Nau, 2004.

TOMASELLO, M. Origens culturais da aquisição do conhecimento humano. São Paulo: Martins Fontes, 2003.

Recebido: 28 abr. 2015

Aprovado: 25 jan. 2017

DOI: $10.3895 /$ rl.v18n23.2912

Como citar: FREITAS, N.L. Memória e linguagem: uma abordagem sociocognitiva. R. Letras, Curitiba, v. 18, n. 23, p. 19-35, jan./jul. 2017. Disponível em: <https://periodicos.utfpr.edu.br/rl>. Acesso em: XXX. Direito autoral: Este artigo está licenciado sob os termos da Licença Creative Commons-Atribuição 4.0 Internacional.

\section{(c) (1)}

